\title{
Cuestiones de terminología en torno al procedimiento artístico del esgrafiado y sus variantes técnicas
}

\author{
Questions of terminology around the artistic \\ method of sgraffito and its technical variants
}

REsUMEN: La técnica del esgrafiado, a pesar de su larga existencia y su presencia en buena parte del mundo, es una gran desconocida. Este artículo aborda cuestiones básicas, necesarias e imprescindibles para cualquier acercamiento a sus manifestaciones, dada la gran confusión y falta de rigor que existe en buena parte de la bibliografía nacional y extranjera. Se reúnen aquí todos los términos con los que es y ha sido conocida esta técnica, analizando las características de cada uno de ellos, su procedencia, ámbito de utilización e implicaciones históricas. Por otro lado, se compendian todas las variantes técnicas que se agrupan bajo el genérico nombre de "esgrafiado".

Palabras clave: Esgrafiado, Revestimientos murales, Ornamentación, Técnica artística, Fachada, Argamasa.

AвstRAct: The Sgraffito technique, despite its long existence and presence in many parts of the world, is a great unknown. This article speaks about basic, necessary and essential topics for any approach to its examples, because of the great confusion and lack of rigor that exists in most of the national and foreign bibliography. Here we have collected all the terms that exist and has been known to call this technique, analyzing the characteristics of each of them, their origins, uses and historical implications. On the other hand, here is possible to find a classification of all the technical alternatives that are grouped under the generic name of "Sgraffito".

Keys words: Sgraffito, Wall coverings, Ornament, Artistic technique, Façade, Plaster.

\section{INTRODUCCIÓN}

A lo largo de los últimos veinticinco años estamos asistiendo a un despertar en el interés por el esgrafiado, una técnica artística que ha permanecido largo tiempo arrin- conada, por lo que todavía sigue siendo una gran desconocida. Contradictoriamente, en muy poco ha favorecido a su conocimiento el hecho de aparecer involucrada en destacados edificios, trayectorias de relevantes creadores, fenómenos urbanísticos, tratados 
teóricos y movimientos artísticos realmente trascendentales para la Historia del Arte. Seguramente, detrás de tan extraña realidad, se hallen fenómenos tales como la tradicional consideración de las artes decorativas como "artes menores"; la valoración peyorativa del revestimiento como un elemento atectónico y por tanto enmascarador de los componentes propiamente arquitectónicos ${ }^{1}$; el secreto que rodea a sus diferentes procesos, guardados con celo por los artesanos; el hecho de que los revestimientos se hayan entendido como una "piel" mudable o "superficie de sacrificio" ${ }^{\prime 2}$, frente a la permanencia del resto de elementos arquitectónicos; el rechazo hacia este tipo de revestimientos por parte de voces "autorizadas" de la teoría arquitectónica moderna y contemporánea ${ }^{3}$,

${ }^{1}$ Eduard Sekler, en su ensayo "Structure, Construction and Tectonics", definió "atectónico" como "término [que] describe bien la forma en que se rechaza $u$ oculta visualmente la interacción expresiva de la carga y el soporte en la arquitectura". E. SEKLER, "The Stoclet House by Josef Hoffmann" en Essays in the History of Architecture presented to Rudolf Wittkower, Londres, 1967, pp. 320-231, apud K. FRAMPTON, Estudios sobre cultura tectónica. Poéticas de la construcción en la arquitectura de los siglos XIX y XX, Madrid, 1999, p. 31.

${ }^{2}$ M. ERRICO, S. S. FINOZZI e I. GIGLIO, “Ricognizione e schedatura delle facciate affrescate e graffite a Roma nei secoli XV e XVI", Bollettino d'arte, $\mathrm{n}^{\mathrm{o}}$ 33-34, 1985, p. 53.

${ }^{3}$ Una de las excepciones más destacadas fue la defensa del revestimiento por parte de Adolf Loos, al que concedió la primacía sobre otros aspectos de la construcción, en consonancia con las ideas del revestimiento textil de Gottfried Semper. Véase a este respecto su ensayo "El principio del Revestimiento" (1898). Sin embargo, voces tan destacadas como la de Viollet-leDuc establecen una fuerte diferenciación entre esencia y apariencia, negándole a la arquitectura que pueda aplicársele el calificativo de "bella" en función de su revestimiento externo, puesto que tal categoría debía referirse a su forma. Con posterioridad, nuevas opiniones vinieron a refrendar esta postura, como bien ha resumido Henry Mallgrave: "Konrad Fiedler sugería que, en las obras modernas, la antigua arquitectura debía desnudarse de su vestimenta para explotar la posibilidad pura del muro. August Schmarsow tomó en consideración esta sugerencia y la desarrolló ampliamente en una conferencia de 1893, donde rechazaba en concreto los atributos decorativos del "arte del vestir" (Bekleidungskunst) a favor de la capacidad abstracta de la etc. Todo ello ha redundado en un terrible menosprecio, cuyas consecuencias más devastadoras han sido el criterio de eliminar revocos como el que nos ocupa, a fin de dejar vistas las fábricas de los edificios, o su sustitución por réplicas realizadas con modernos morteros industriales. Se ha anulado así, la última fase del proceso constructivo, connatural a todo edificio para su protección y embellecimiento, privándonos de la imagen original que un día fue configurada por arquitectos, comitentes y artesanos. Por fortuna, son muchas las voces que se han alzado contra la sangrante destrucción de este patrimonio y, de hecho, la creciente bibliografía que va surgiendo dentro y fuera de España, pone especial énfasis en esta cuestión ${ }^{4}$.

arquitectura para "crear espacio" (Raumgestalterein)". H. MALGRAVE, "Introducción a Semper", en The Four Elements of Architecture and Other Writings, p. 42, apud K. FRAMPTON, Op. cit., p. 27.

${ }^{4}$ Entre los trabajos monográficos más relevantes de los últimos veinticinco años en nuestro país -además de los mencionados en las otras notas de este artículo- hay que destacar: A. DE LA PUENTE ROBLES, El esgrafiado en Segovia y Provincia, Segovia, 1990. M. D. CAMPOS SÁNCHEZ-BORDONA, "Los esgrafiados del Convento de Nuestra Señora de la Concepción de Villafranca del Bierzo (León)", Estudios humanísticos, geografía, historia, arte, no 15, 1993, pp. 207-224. N. MARTÍ I PORTA, "Aportació a l'estudi dels esgrafiats de Montblanc", Aplec de treballs del Centre d'Estudis de la Conca de Barberá. Montblanc, no 11, 1993, pp. 93169. X. SITJES I MOLINS, "Els estucats esgrafiats", Dovella, no 45-46, 1993, pp. 41-45. A. BRAVO NIETO, "El estuco esgrafiado. Colores y formas en la arquitectura melillense de la primera mitad del siglo XX", Boletín de Arte, nº 20, 1999, pp. 593-616. J. M. LLODRÁ I NOGUERAS, Els esgrafiats de l'Església Parroquial de Sant Celoni (1762), Vallgorquina, 1999. J. ESPUPGA, D. BERASATEGUI, y V. GIBERT, Esgrafiats. Teoria i pràctica, Barcelona, 2000. R. RUIZ ALONSO, Los esgrafiados segovianos. Encajes de cal y arena, Segovia, 2000. M. CASAS I HIERRO, "Façanes esgrafiades (I)", Tag, no 22, 2001, pp. 26-31. R. RIPOLL MASFERRER, “La masia i l'esgrafiat barroc. Can Masferrer de Sant Sadurni d'Osormort (segle XVIII)", en El Mas Català durant l'edat mitjana i la moderna (segles IX-XVIII), Anuario de Estudios Medievales annex 42, Barcelona, 2001, pp. 313324. M. CASAS I HIERRO, "Façanes esgrafiades (II)", Tag, no 23, 2001, pp. 25-28. A. FERRER ORTS, "Presencia de la decoración esgrafiada en la arquitectura valenciana (1642-1710)", Boletín del Museo de Instituto Camón Aznar, no 84, 2001, pp. 37-48. R. RUIZ ALON- 
La mayor parte de los trabajos publicados en torno al esgrafiado tiene un marcado acento local, primando el estudio de los edi-

SO, El esgrafiado en Segovia, Madrid, 2001. J. ORANTOS GONZÁLEZ, "Recuperación de esgrafiados", Bia. Aparejadores de Madrid, no 219, 2002, pp. 99-114. C. BOSCH CARRERA, La pell de les cases. L'esgrafiat a Lleida, del barroc al noucentisme, Lleida, 2003. A. FERRER ORTS, L'esplendor de la decoració esgrafiada valenciana (16421710). La seua presència en l'arquitectura religiosa de Xirivella, Xirivella, 2003. J. ORANTOS GONZÁLEZ, “Recuperación de esgrafiados de la fachada de la Ermita de la Salud de Plasencia", Ars Sacra, no 26-27, 2003, pp. 101-106. J. ORELLANA PIZARRO, F. SANZ FERNÁNDEZ, y M. SANZ SALAZAR, “La decoración y articulación de paramentos arquitectónicos en la ciudad de Trujillo: los esgrafiados a la cal", XXXV Coloquios Arquitectónicos de Extremadura, 2006, pp. 679-700. F. GONZÁLEZ YUNTA, "La técnica tradicional del esgrafiado con mortero de cal. Un recurso publicitario actual", I Jornada Nacional de Investigación en edificación, Madrid, 2007, s.p. M. A. GILSANZ MAYOR y M. F. MARTÍNEZ SERRANO, "Grupos de simetría en el esgrafiado segoviano", I Jornada Nacional de Investigación en edificación, Madrid, 2007, s.p. R. RUIZ ALONSO, "Evolución histórica del esgrafiado en España", Estudios Segovianos, no 108, 2008, pp. 145-195. V. MONTANARI, "La técnica de la decoración mural "a graffito" en el acabado de las superficies arquitectónicas. El Palacio de la Cancilleria Vecchia a Roma: análisis y problemas de conservación", en V.V.A.A. (ed.), Actas del Sexto Congreso Nacional de Historia de la Construcción, Valencia, 21-24 octubre 2009, Madrid, 2009, pp. 901-908. R. RUIZ ALONSO, "El esgrafiado", en V.V.A.A., Las Artes Decorativas en el Urbanismo Español, Madrid, 2009, pp. 76-83, 140-151 y 266-279. J. M. GÓMEZ LOZANO y A. FERRER ORTS, "Els esgrafiats de la Cartoixa de Valldecrist. Una proposta de reconstrucció", Ars Lon$g a, \mathrm{n}^{\mathrm{o}} 19,2010$, pp. 109-114. A. FERRER ORTS, "El esgrafiado arquitectónico valenciano y su irradiación a Cataluña y Aragón", Butlletí de la Reial Acadèmia Catalana de Belles Arts de Sant Jordi, no 23-24, 2009-2010, pp. 227-232. F. SANZ FERNÁNDEZ, El Color de la Arquitectura en Trujillo. Pintura de fachadas, esgrafiados y pintura mural durante el Renacimiento, Cáceres, 2011. F. VEGA BALLESTEROS y S. AGUIRRE SIERRA, El esgrafiado en la comarca de la Carballeda, Zamora, 2011. F. SANZ FERNÁNDEZ, "Esgrafiados, encintados y enjalbegados renacentistas en torno al curso medio-bajo del río Tagia", en M.M. LOZANO BARTOLOZZI, V. MÉNDEZ HERNÁN y E. ASENJO RUBIO, (coords.), Paisajes modelados por el agua: entre el arte y la ingeniería, Mérida, 2012, pp. 445-461. J. FERNÁNDEZ ORTEA, "Los esgrafiados del término municipal de Sigüenza", en XIV Encuentro de Historiadores del Valle del Henares, Alcalá de Henares 27-30 noviembre 2014, Madrid, 2014, pp. 603-625. ficios y de la ornamentación por encima de las cuestiones técnicas, sobre las que se pasa de puntillas o directamente se obvian. Es ésta una materia ciertamente espinosa, puesto que el esgrafiado abarca un considerable número de procesos técnicos, de los que se deriva un sorprendente y muy diferenciado abanico de realizaciones, pudiendo llegar a desorientar a quien no esté familiarizado con sus particularidades. El fenómeno viene de muy atrás, como ya observó Salvador Bernal Martín al analizar el artículo que Francisco Alcántara había publicado en 1909, en el que "nada dice del esgrafiado, limitándose a referirse al revoco que en una ocasión, denomina estuco" $^{\prime \prime}$ (Fig. 1); cuando no ha quedado más remedio, los investigadores han apelado a expresiones descriptivas del tipo "falso despiece de sillería", "recurso del encintado", "fajas enlucidas", "estuco de cal tipo relieve", "fajas de mortero", etc. ${ }^{6}$, e incluso se puede llegar a leer que se trata de una pintura "a la cal"7. Añadamos otra rémora más a la comprensión de este complejo panorama: las propias fuentes documentales son escasas y confusas. El proyecto de investigación "Corrientes Nacionales e Internacionales del Esgrafiado", apoyado por el Instituto de Cultura Tradicional "Manuel González Herrero" y por la Real Academia de Historia y Arte de San Quirce, me ha permitido observar el preocupante alcance de estos fenómenos, siendo necesario aportar al mundo de la investigación una clarificación técnica y un léxico común que trascienda las especificidades que imponen las fronteras políticas o naturales.

${ }^{5}$ S. BERNAL MARTÍN, “Notas para la historia del revoco segoviano" en F. ALCÁNTARA, L. F. DE PEÑALOSA Y CONTRERAS y S. BERNAL MARTIN, Los esgrafiados segovianos, Segovia, 1971, p. 25, n. 21.

${ }^{6}$ R. CÓRDOBA DE LA LLAVE, "Fortificaciones Almohades de la provincia de Córdoba" en M. VALOR PIECHOTTA, J. L. VILLAR IGLESIAS y J. RAMÍREZ DEL RÍO, Los Almohades, su patrimonio arquitectónico y arqueológico en el sur de al-Andalus, Sevilla, 2004, p. 125.

${ }^{7}$ S. MACIAS, "Moura na baixa idade média: elementos para um estudo histórico e arqueológico", Arqueologia Medieval, nº 2, 1993, p. 129. 


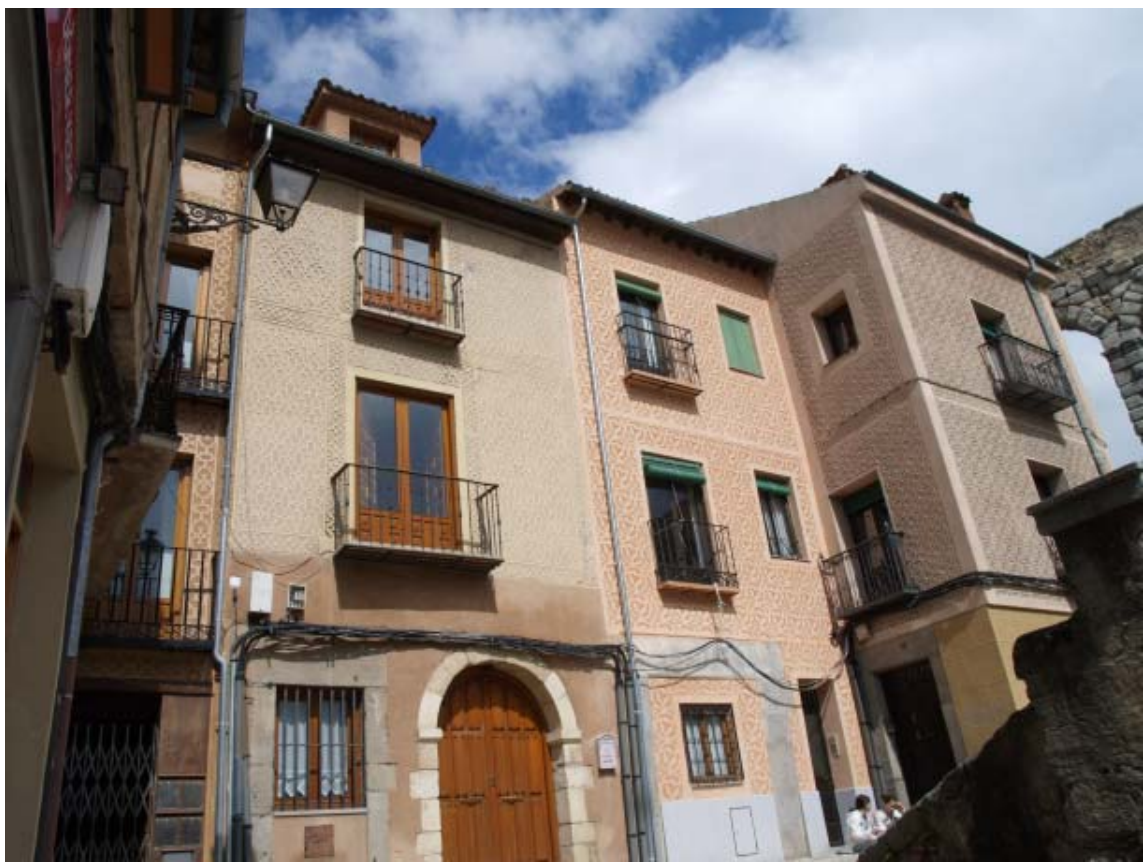

- Fig. 1. Aspecto de una calle con fachadas esgrafiadas en Segovia. Foto del autor.

\section{DEFINICIÓN DE ESGRAFIADO}

La forma más sencilla de explicar qué es técnicamente un esgrafiado, es decir que se trata de un dibujo que se hace patente por el método de extraer materia, tal y como se deriva de su raíz etimológica, compuesta de dos palabras latinas, ex -que significa "fuera"- y grapheim -“dibujo"-; así lo explica Roque Barcia en su renombrado Primer Diccionario General Etimológico de la Lengua Española ${ }^{8}$ Su etimología puede ponerse también en relación con términos griegos como graphos -"trazar", "dibujar", "escribir"- o graphein -"escribir"-, y con la palabra latina graphium, nombre de un estilete o varilla delgada, cuya afilada punta servía, precisamente, para escribir sobre tablillas de arcilla o de cera. De estas raíces derivan buena parte de los vocablos con que hoy es conocido: "esgrafiado" en castellano, esgrafito en portugués, sgraffito en italiano, alemán, inglés, albanés, checo, etc., sgraffio y sgraffiato también en italiano, égratigne, esgratigné y sgraffite en francés, sgrafita y sgraffita en checo y polaco respectivamente, scraffito a veces en

${ }^{8}$ Entrada para el vocablo "esgrafiado" en R. BARCIA, Primer Diccionario General Etimológico de la Lengua Española, Madrid, 1880-1883, t. 3, p. 263. inglés, esgrafiat $-\mathrm{y}$, menos frecuentemente, escarpat- en catalán, etc. (Fig. 2).

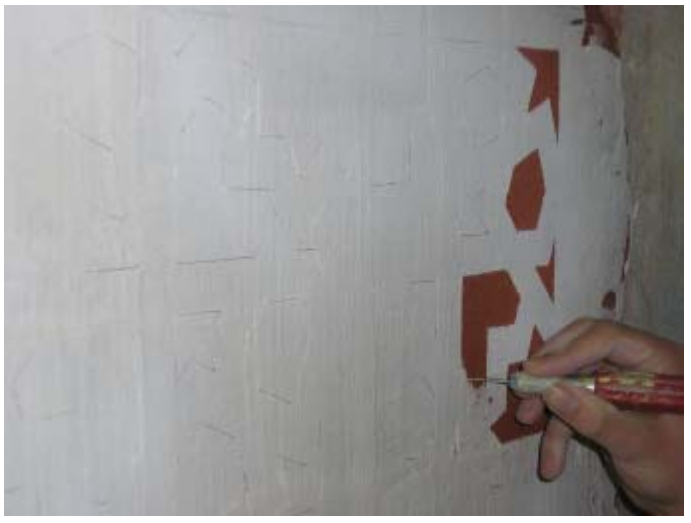

- Fig. 2. Proceso de esgrafiado en la variante técnica del "acabado en cal". Foto: Mari Mar Nevado.

EL ESGRAFIADO MURAL Y SUS VARIANTES TÉCNICAS

El esgrafiado participa como fase en muchas tecnologías artísticas; por ello hemos de acotar nuestro principal radio de acción a aquellas manifestaciones comprendidas en el ámbito de los "revestimientos murales", y dentro de ellos, a la familia de los "revo$\cos ^{\prime \prime}$. Este grupo se caracteriza por emplear 
para su confección determinados morteros o argamasas, integrados por un conglomerante (el más habitual va a ser la cal), un material de armar (fundamentalmente la arena) y agua, pudiendo recibir igualmente otros ingredientes con el objeto de reforzar su resistencia y adherencia (caseína, ladrillo machacado...) o de dotar al resultado de coloraciones alternativas a las aportadas por la arena (pigmentos, ceniza, etc.). Otra característica de los revocos es que se confeccionan en base a capas o "tendidos" que se extienden sobre una preparación de fondo llamada "enfoscado". El número y peculiaridades de estos tendidos son el mejor fundamento a la hora de clasificar los diferentes tipos de esgrafiado mural.

El "esgrafiado a un tendido" emplea, consecuentemente, una sola capa de mortero, que es extendida y pulimentada a llana. Antes de que el tendido haya endurecido, ha de perfilarse la decoración con un utensilio afilado que deja su impronta a modo de fino tajo continuo y excavado. A veces, la decoración se detiene en este punto, pudiendo denominarse a tales manifestaciones con el apelativo de "grafito inciso" -de forma genérica- o con el de "agramilado" -de forma particular-, si en su consecución se emplea el gramil. Sin embargo, lo más frecuente es que después del grabado se rasque ("esgrafíe") superficialmente el interior de los diseños para propiciar un fondo rugoso que contraste con las zonas lisas en reserva.

El "esgrafiado a dos tendidos", lógicamente, se caracteriza por la superposición de dos capas, frecuentemente de diferentes colores. Aquí, tras el pulimentado y el delineado por incisión del motivo ornamental, se excavan los fondos hasta descubrir el primer tendido, de modo que la decoración superficial va a ser lisa y en relieve, mientras que el fondo quedará en profundidad y con una textura rugosa.

El "esgrafiado con acabado en cal" es una variante del anterior, en la que el segundo tendido es sustituido por una lechada de cal aplicada a brocha, caracterizándose por su pequeño relieve y contraste cromático.

Existen diferentes variantes de lo que a algunos albañiles hemos oído llamar "bocadillo" y que más propiamente debe denominarse "esgrafiado embutido", de acuerdo a la definición que Antonio Palomino nos brindó de la "Pintura Embutida"9. Otros sinónimos que pueden emplearse son "esgrafiado taraceado" y "mosaico de cemento", nombre este último debido a uno de sus inventores, el arquitecto y constructor J. F. Holm, según explica en su manual Instrucciones para hacer pinturas al fresco, estuco y mosaico de cemento. Un libro basado en la experiencia práctica, particularmente del Museo Thorvaldsen. Para arquitectos, pintores y albañiles, editado en $1850^{10}$. Básicamente, se trata de un esgrafiado a un tendido, cuyas diferentes partes van a ser literalmente vaciadas hasta descubrir el enfoscado; cada uno de los huecos, conforme a un cartón previamente definido, será colmatado con argamasas de diferentes colores, que quedarán en un mismo plano, como si se tratara de una pintura (Fig. 3). A lo largo del siglo XIX, el esgrafiado taraceado se combinará de diferentes formas con el esgrafiado a dos tendidos, multiplicando sus efectos ornamentales al incorporar el relieve.

\footnotetext{
9 "Esta imita la naturaleza, embutiendo fragmentos de varias materias, con la debida union, según conviene á lo que intenta representar. $\mathrm{Y}$ respecto de que las materias con que estos se executa son diferentes, de que procede el serlo sus operaciones; pues unas se hacen con metales, otras con piedras, otras con maderas, y otras con pasta [...] Es especie propiamente de pintura embutida, porque formados los senos de lo que se ha de executar en la pasta del tablero principal, se van introduciendo en ellos pastas de diferentes colores según lo pide la pintura..." A. PALOMINO, El Museo Pictórico y Escala Óptica. Teórica de la Pintura, en que se describe su origen, esencia, especies y qualidades, con todos los demas accidentes que la enriquecen é ilustran. Y se prueban con demonstraciones matematicas y filosoficas sus mas radicales fundamentos. Por Don Antonio Palomino de Castro y Velasco, Madrid, 1795, lib. I, pp. 40 y 42.

${ }^{10} \mathrm{~J}$. F. HOLM, Veiledning ved Udförelsen af Frescomalerier, Stuk og Cementmosaik. En paa praktiske Erfaringer, især fra Thorvaldsens Museum, stöttet Haandbog. For Architekter, malere og murere, Copenhaguen, 1850.
} 


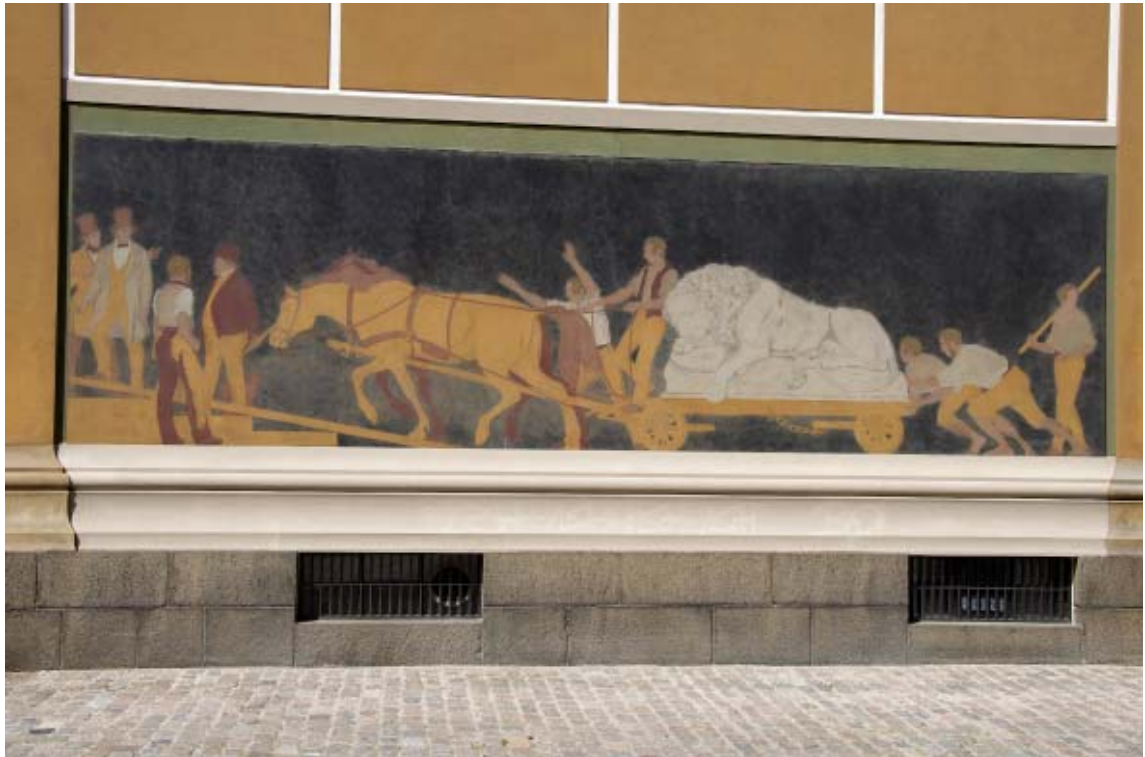

- Fig. 3. Aspecto parcial de la decoración externa del Museo Thorvaldsen de Copenhague. Foto del autor.

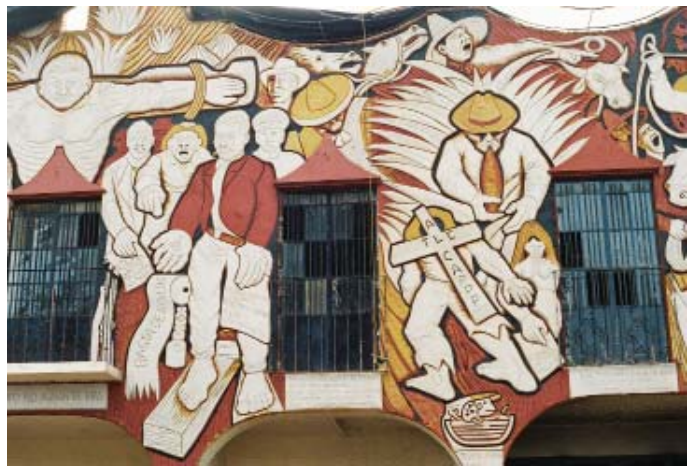

- Fig. 4. Detalle del mural "El Campo no aguanta más", realizado por el artista Ariosto Otero en el edificio Ejidal de San Nicolás, Delegación Magdalena Contreras, Ciudad de México. Foto: Ariosto Otero.

En la traducción de uno de los mejores manuales de revestimientos que se han escrito, Yesería y estuco, de Karl Lade y Adolf Winkler (su primera edición alemana es de 1952), se mencionan los "esgrafiados de varias capas" y los "esgrafiados raspados"11. Los primeros superponen más de dos tendidos con coloraciones diferentes, de lo que también se deriva una multiplicidad de planos. Esta variante se usó mucho en Centroeuropa, sobre todo a partir de la Segunda Guerra Mundial, pero es en el muralismo latino-

${ }^{11} \mathrm{~K}$. LADE y A. WINKLER, Yesería y estuco, Barcelona, 1960, pp. 145 y ss.

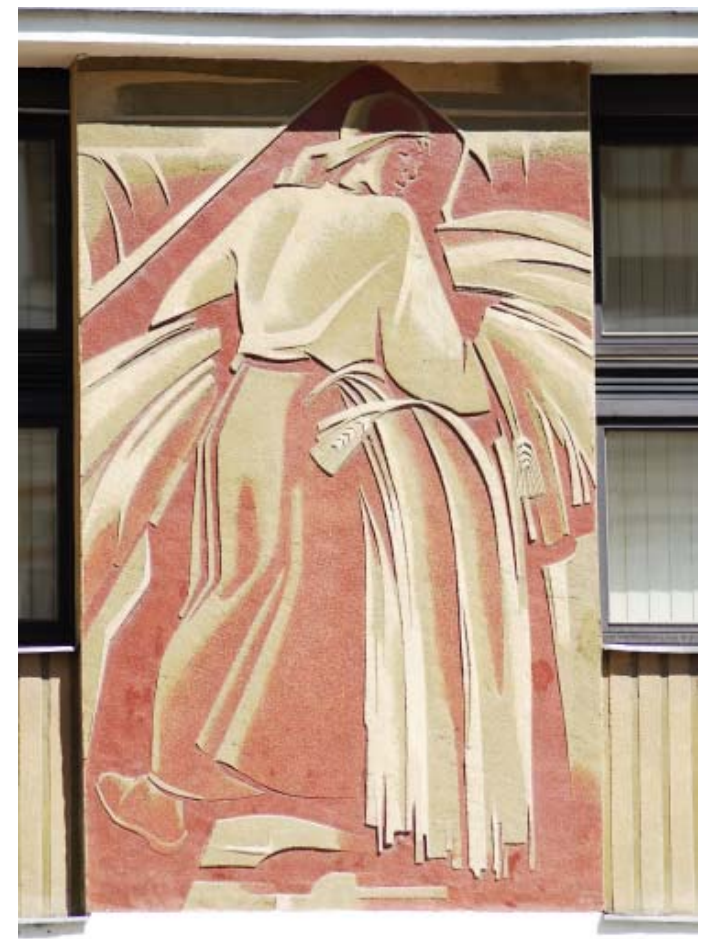

- Fig. 5. Mural comercial ejecutado por Heinrich Ebner en Viena, fechado en 1957. Foto del autor.

americano actual donde se está empleando con más asiduidad, aplicándolo a unas realizaciones que buscan el impacto de formas y colores para transmitir su fuerte carga social, contestataria y reivindicativa (Fig. 4). Los "esgrafiados raspados" se distinguen de los anteriores por buscar en su consecución sua- 
ves transiciones entre los tendidos de diferentes colores, al objeto de propiciar medias tintas. Una de sus máximas expresiones en España es la fachada neobarroca de la Casa Masferrer en la localidad de Vic (Barcelona), pero desde mi punto de vista, su más consumado maestro fue el austriaco Heinrich Ebner, con producciones realmente admirables en los años centrales del siglo pasado (Fig. 5).

\section{EL ESGRAFIADO MURAL EN SU TERMINOLOGÍA}

Rara vez la investigación desciende a detallar estas cuestiones técnicas, identificando a las manifestaciones por términos genéricos que conviene igualmente conocer en sus peculiaridades, si queremos emplearlos con toda propiedad.

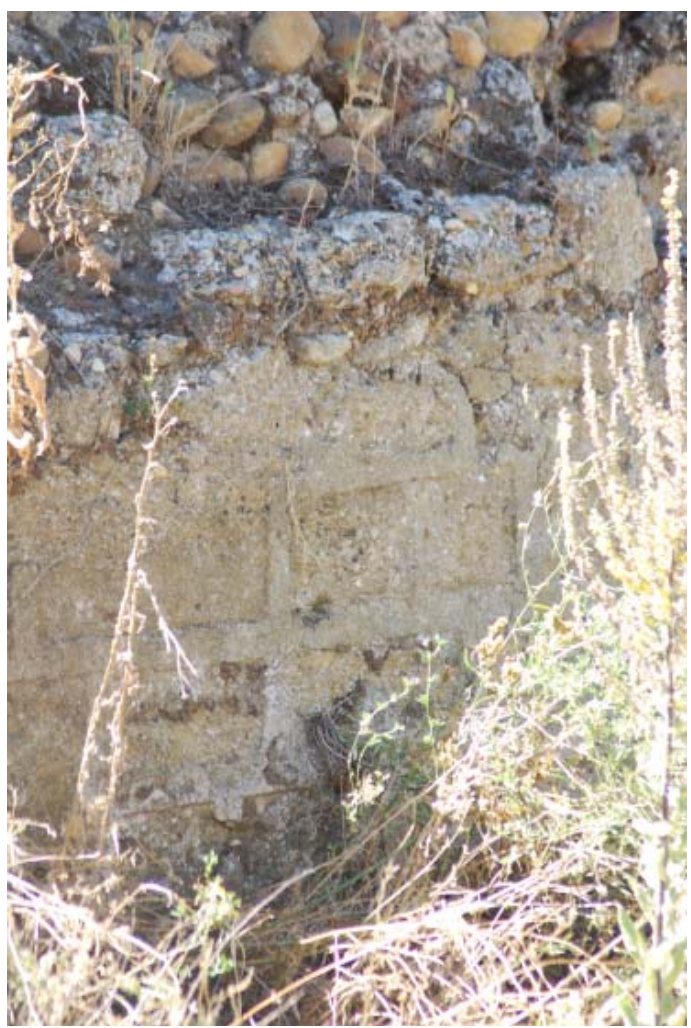

- Fig. 6. Esgrafiado a un tendido sobre la cabecera de la basílica de Marialba de la Ribera en Villaturiel, León. Foto del autor.

El vocablo "esgrafiado", aplicado tanto al procedimiento de revestimiento mural como al trabajo artístico con él realizado, apa- rece en nuestro país muy tardíamente, sobre todo si tenemos en cuenta que las evidencias más antiguas de esta técnica nos remontan en suelo hispano hasta el siglo IV, tal y como atestigua la cabecera de la basílica paleocristiana de Marialba de la Ribera (Villaturiel, León). Allí aparece ya configurado el esgrafiado a un tendido, aunque en algunos puntos se prefirió escarbar la superficie del revoco hasta dejar vista la mampostería (Fig. 6).

Desconocemos qué nombre recibió tal procedimiento entonces, pero lo cierto es que acabó imponiéndose el italianismo "esgrafiado". La razón debió estribar en la difusión desde Italia del esgrafiado con acabado en cal durante el siglo XVI, asentándose en numerosos lugares de Europa, entre ellos España $^{12}$. A ello debemos unir que la primera descripción técnica con que contamos se refirió precisamente a esta variante y que además apareció en una influyente obra, Las vidas, de Giorgio Vasari (1550) ${ }^{13}$. Fue él quien nos informó de que en su proceso se empleaba una herramienta de hierro que hacía rayas, denominado ferro graffiato, nombre del que los pittori hicieron derivar el apelativo de este procedimiento ${ }^{14}$.

Apoyándose en tales premisas, el mundo científico internacional consideró la aparición y propagación de este procedimiento específico desde Italia como testimonio del nacimiento y difusión del esgrafiado en general, ignorando la existencia en la Península Ibérica de manifestaciones altomedievales, islámicas y mudéjares, notablemente anteriores -podemos sumar algunas más en el norte de África-, en las que además se practicaron otras vertientes técnicas del esgrafiado con total autonomía de las experiencias italianas,

${ }^{12}$ R. RUIZ ALONSO, El esgrafiado. Un revestimiento mural en la provincia de Segovia, Segovia, 1998, p. 42.

${ }^{13}$ G. VASARI, Le vite de' piu eccellenti Pittori, Scultori e Architettori, Florencia, 1568, cap. XXVI, p. 38. He tratado monográficamente de la incidencia de este tipo de esgrafiado en nuestro país en el artículo R. RUIZ ALONSO, "Aspectos del esgrafiado en el Renacimiento español", Goya, nº 348, 2014, p. 209.

${ }^{14}$ G. VASARI, Op. cit., p. 38. 
caso de los esgrafiados a uno y dos tendidos ${ }^{15}$. La antigüedad de este último procedimiento nos lleva, al menos, hasta los hallazgos del yacimiento arqueológico de Madinat Ilbira (Granada), cuya cronología ha de situarse entre el siglo X y los inicios del XI (Fig. 7). A pesar de ello, la creencia de que el esgrafiado fue una invención italiana encontró acomodo en nuestro país. Realmente valiosa a este respecto es la observación que en su día hizo Vicente Carducho, al insertar en sus Diálogos de la pintura (1633) el nombre de grafio para referirse inequívocamente a nuestro procedimiento, puntualizando además el origen del término: "Algunas vozes ai Italianas, como es esfumar, coza, gofa, efuelto, actitud, mórbido, esbatimento, grafio; mas son tan platicadas ya en España, que vienen a ser propias" ${ }^{\prime 16}$. Por esos mismos años, Francisco Pacheco emplea el vocablo tal y como hoy figura en nuestra lengua, al mencionar diferentes disciplinas pictóricas, entre ellas "el esgrafiar las fachadas"17. En Francia estaba ocurriendo algo semejante, puesto que André Félibien, en su tratado Principios de Arquitectura, Escultura, Pintura y otras artes (1676), afirma: “Todavía hay otra manera de pintura blanco y negro: que es como el fresco, y que se mantiene al aire; los italianos lo llaman Sgraffitto, que significa Esgrafiado [Esgratigné]"18. Mucho después, en 1887 se pu-

15 De la infinidad de afirmaciones erróneas que podrían traerse a colación, reseñamos una de las más recientes en J. VONCKEN, "Das Wiederaufleben der sgraffitotechnik im 19. Jahrhundert", en Le facciate a sgraffito in Europa e il restauro della facciata del Palazzo Racani-Arroni in Spoleto. Atti della giornata di studio. Spoleto, 23 settembre 2000, Spoleto, 2000, p. 35.

${ }^{16} \mathrm{~V}$. CARDUCHO, Dialogos de la pintura, su defensa, origen, essencia, definicion, modos y diferencias. Al gran Monarcha delas Españas y Nuevo Mundo, don Felipe IIII. Por Vicencio Carducho, de la Ilustre Academia de la nobilissima ciudad de Florencia y pintor desu Mag. Catolica, Síguense a los Dialogos, Informaciones y pareceres en sabor del Arte, escritas por varones insignes en todas letras, [Madrid], 1633, p. 134.

${ }^{17}$ F. PACHECO, Arte de la Pintora, su antigvedad, y grandezas, Sevilla, 1649, p. 29. La obra se editó póstumamente en 1649, pero se debió escribir unos diez años antes.

18 A. FÉLIBIEN, Principes de l'Architecture, de la Sculpture, de la Peinture, et des autres arts, qui en dépendent. blica la versión en castellano del Vocabulario de términos de arte, escrito por J. Adeline, pero traducido y revisado por José Ramón Mélida; en este diccionario no aparece el término "esgrafiado", sino: "Esgrafito.- (Sgraffite) Moda de decoración italiana. Especie de pintura al fresco, que consiste en aplicar sobre un fondo de estuco negro una pasta blanca, ó sobre fondo claro pasta de color obscuro, pero levantada por surcos de manera que forma dibujos. También suele decirse, á la italiana, sgraffito e impropiamente sgraffiti"19.

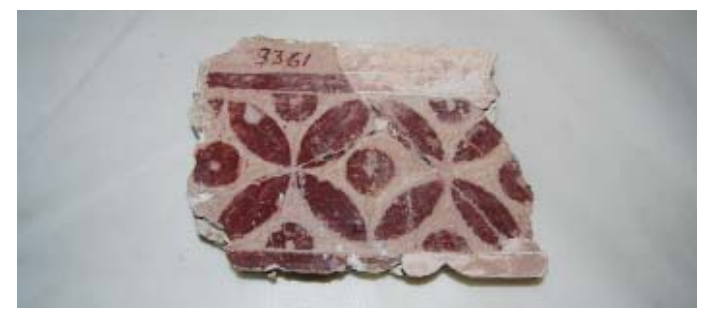

- Fig. 7. Esgrafiado a dos tendidos sobre un fragmento de revoco aparecido en la antigua ciudad de Madinat Ilbira (Granada), depositado en el Museo Arqueológico y Etnológico de Granada. Foto del autor.

Así pues, todo parece indicar que técnica y denominación quedaron identificadas en Italia, que allí al esgrafiado se le consideró una disciplina pictórica y que así fue asimilado por el resto de Europa a partir del siglo XVI (Fig. 8).

No obstante, sgraffito es una palabra tardía en la documentación, incluso en la italiana. Tal vez su primera aparición en el contexto que nos interesa corresponda a la contabilidad que atañe a la reforma que Filippo di Matteo Strozzi estaba acometiendo en una casa de labor en la localidad de Santuccio, donde se consigna el 16 de octubre de 1484 el pago al pintor Bernardo di Stefano Rosselli-

Avec un dictionnaire des Termes propres à chacum de ces Arts. Par M. Felibien, Secretaire de l'Accademie des Sciences, $\mathcal{E}$ Historiographe des Bastimens du Roy, Paris, 1697, p. 303.

${ }^{19} \mathrm{~J}$. ADELINE, Vocabulario de términos de arte, escrito en francés por J. Adeline, traducido, aumentado con más de 600 voces y anotado por José Ramón Mélida, del cuerpo de Archiveros, Bibliotecarios y Anticuarios, adscrito al Museo Arqueológico Nacional, Madrid, 1887, p. 237. 


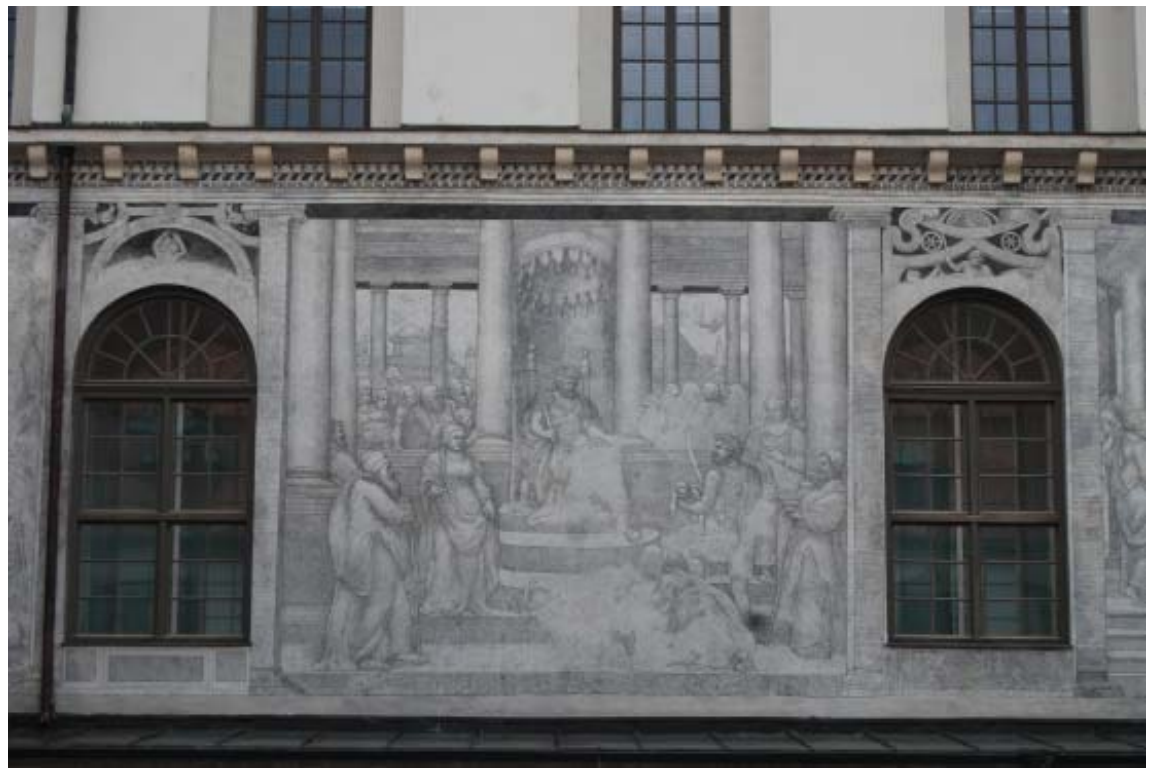

- Fig. 8. Juicio de Salomón en los esgrafiados del Castillo de Neoburgo, Alemania. Foto del autor. no "per isgraffiare fregi e archali e pilastri" 20 . Sin embargo, ello no significa que el término se hubiera impuesto sobre otras opciones.

El pintor y teórico español Pablo de Céspedes, en su Discurso de la comparación de la antigua y moderna pintura y escultura (1604), quiso establecer una clasificación de los diferentes tipos de pintura, recurriendo, no sólo a sus conocimientos, sino también a las fuentes escritas; así, trató un tanto confusamente de "La pintura, llamada de los antiguos monochromaton, y la que llamaron linnearis" que a su parecer "es poco diferente la una de la otra", puntualizando que "Entendiera que monocromata eran las pinturas de blanco y negro, si Plinio no hiciese particular mención de ellas, llamándolas Monocromata ex albo" ${ }^{21}$; lástima que no se extendiera algo más. La Historia Natural de Plinio no nos ayuda, pero esa "monocromía a partir [o extraída] del blanco", pudiera entenderse quizá como una antigua expresión para definir el "esgrafiado con acabado en cal". Interesantísimas son también las palabras de Céspedes por intentar distinguir la pintura "de blanco

${ }^{20}$ A. HUTH, "Albaria insignita. Zur Technologie der Sgraffito-Dekorationen des 15. Jahrhunderts in Florenz", Zeitschrift für Kunsttechnologie und Konservierung, jul. 2014, p. 8.

${ }^{21}$ P. DE CÉSPEDES, Op. cit., pp. 280, 295 y 297. y negro" de esta otra disciplina, puesto que los testimonios de tratadistas y escritores no siempre las diferencian. La grisalla mural adquirió en la Italia del Renacimiento un enorme desarrollo, expandiéndose -como el esgrafiado- por buena parte de Europa e incluso arraigando con fuerza en lugares como México. La cercanía visual con el esgrafiado era estrecha, puesto que en éste, el tendido de fondo se teñía con ceniza o carbón, de manera que en el resultado se destacaban las figuras blancas sobre un fondo gris o negro; por si fuera poco, a veces se retocaban las superficies encaladas con aguada de color gris al objeto de imprimir una sensación de volumen. Para complicar más las cosas, sabemos que artistas como Andrea di Cosimo Feltrini, Bernardino Barbatelli -conocido también como "Poccetti" - o el tándem Polidoro da Caravaggio-Maturino Fiorentino practicaron ambas disciplinas ${ }^{22}$. Por todo ello, debe imponerse la prudencia a la hora de interpretar las fuentes ${ }^{23}$.

${ }^{22}$ G. VASARI, Op. cit., p. 651. De estos dos últimos nos informa que "Fecero in Borgo Nuovo una facciata di graffito, e ful Canto della Pace un'altra di graffito fimilmente".

\footnotetext{
${ }^{23}$ Algunas de las referidas a España han sido recogidas por A. FERRER ORTS, "Sobre la decoración esgrafiada en el Barroco Español", Ars Longa, vol. 9-10, 2000, pp. 105-109.
} 
Leon Battista Alberti también parece referirse al esgrafiado con acabado en cal, al afirmar en De re aedificatoria (1452): "y puedese ver por el cõntrario de los rusticos edificios de los antiguos, paredes allegadas de piedra incierta, menuda y obra allegadiza, en las quales estan con ordenes igualadas con colores vna vez, y otra distinguydas de blanco y negro, de suerte que por la delicadeza de la obra no se puede mas dessear, pero estas cosas quiza pertenecen mas a aquella parte de la pared que se diz encostrar [...] Esta encostracion es de muchas maneras, blanca pura, con señales, pintada, entablada, cortada, vidriada y mezclada de estas partes" ${ }^{\prime 24}$. Andreas Huth ha querido ver en estas palabras una alusión a nuestro procedimiento ${ }^{25}$, nombrado en la traducción que hemos manejado como "blanco con señales" y en el texto original latino como albaria insignita, lo que podría estar en línea con la reflexión de Céspedes a partir de Plinio.

El humanista Paolo Cortesi, en su libro De Cardinalatu (1510), incluye nuestra técnica entre los dignos acabados que pueden recibir las residencias de los prelados, nombrándola como cementitia structura o tectorio uti scalpturato, poniendo como ejemplo el Palazzo della Rovere en Roma, por entonces propiedad del cardenal Francesco Alidosi ${ }^{26}$. Lo curioso del caso es que en las Annotationes que, ordenadas alfabéticamen-

${ }^{24}$ L. B. ALBERTI, Los Diez Libros Architeçtura de Leon Baptista Alberto. Traduzidos de Latín en Romance. Dirigidos al muy Illustre señor Iuan Fernandez de Espinosa, Thesorero General de su Magestadyde su Cõseso de Hazienda, Madrid, 1582, lib. VI, cap. V, pp. 170-171.

${ }^{25}$ A. LILLIE, Florentine Villas in the Fifteenth Century: an Architectural and Social History, New York, 2005, pp. 119 y ss. A. HUTH, Op. cit., p. 6.

${ }^{26}$... quosdam etiam, qui cementitia structura delectentur, tectorio uti scalpturato malle, qualis modo est F. Ali dosii Ticinensis senatoris, artiicio concinna magis ō mamorum copia sunptuosa domus: quare hec ornamentorum genera ad eam sunt prudentiae terminationem revocanda... P. CORTESI, Pauli Cortesii protonotarii apostolici in libros de cardinalatu ad Iulium Secundum Pont. Max., Castro Cortesio, 1510, lib. II, cap. II., [s. p.]. te al final del texto fueron incorporadas por otros autores, se puntualiza: Scalpturato -a / scalpo, scalpturio, scalptura / scalptū / scalpelei et scalsuratū gēus ì quo albaria tretoria scalpto radunt in supericie, vulgo sgrafiatu vocant; es decir, se hacen constar varios sinónimos latinos de scalpturato, se describe someramente el principio técnico y se puntualiza que comúnmente se llama en latín a este procedimiento sgrafiatum ${ }^{27}$.

Aún mucho tiempo después, Italia sigue ofreciéndonos alguna variante del término. Filippo Baldinucci en su Notizie de' professori del disegno da Cimabue in qua (1681) emplea el término sgraffio ${ }^{28}$, en relación con los trabajos de esgrafiado realizados por Bernardino "Poccetti"; todavía en 1817 volvemos a encontrar idéntico vocablo en la Reale Galleria di Firenze cuando aborda la biografía de este mismo $\operatorname{artista}^{29}$.

Nuestro idioma puede aportar también algunas alternativas al término "oficial", no exentas de curiosidad.

En el claustro del Monasterio Cisterciense de Santa María de Carrizo (Carrizo de la Ribera, León) se "labraron de desflorado" ${ }^{\prime 30}$, a mediados del siglo XVI, sus cuatro pandas; aunque parte de sus esgrafiados han desaparecido, aún quedan amplias suficientes con un programa iconográfico y decorativo realmente singular ${ }^{31}$ (Fig. 9).

\footnotetext{
${ }^{27}$ A. HUTH, Op. cit., pp. 8-9.

${ }^{28}$ F. BALDINUCCI, Delle notizie de'professori del di-
} segno de Cimabue in qua, della parte II. Del secolo IV. Dal MDLX. Al MDLXX, edizione accrescinta di Annotazioni del sig. Domenico Maria Manni, Florencia, 1760, p. 467.

${ }^{29}$ Reale Galleria di Firenze illustrata, vol. I, Firenze, 1817, p. 248

${ }^{30}$ C. CASADO y A. CEA, Los monasterios de Santa María de Carrizo y Santa María de Sandoval, Madrid, 2000, pp. 16 y $35-36$.

${ }^{31}$ M. D. CAMPOS SÁNCHEZ-BORDONA y M. VALDÉS FERNÁNDEZ, "La decoración de esgrafiados en el Monasterio de Santa María de Carrizo (León)", en J. PANIAGUA PÉREZ y M. I. VIFORCOS MARINAS (coords.), Claustros leoneses olvidados. Aportaciones al monacato femenino, Madrid, 1996, pp. 135-146. 


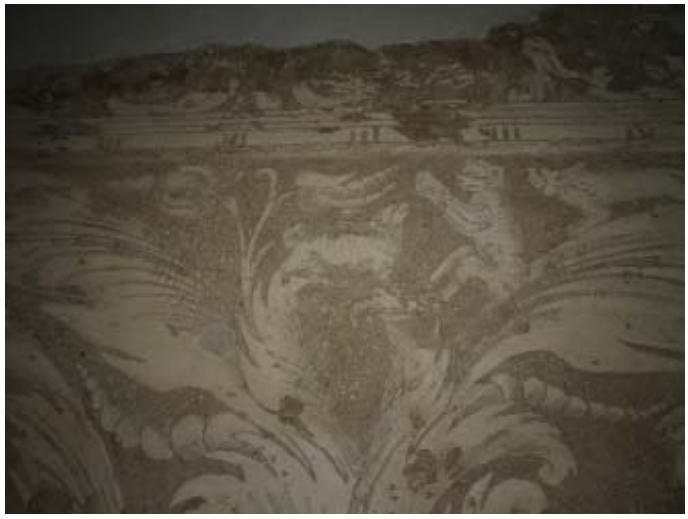

- Fig. 9. Detalle de la decoración esgrafiada que se conserva en el claustro del Monasterio de Santa María de Carrizo en Carrizo de La Ribera, León. Foto del autor.

Muchas de las obras del esgrafiado valenciano del siglo XVII corresponden a renovaciones de templos o a capillas de nueva planta adosadas a ellos; es entonces cuando se restauran y se revisten de flamantes galas que eran denominadas por sus contemporáneos "remiendos" o "composturas"32, nombres bastante acertados puesto que venían a enmascarar los materiales baratos con que se construía (Fig. 10).

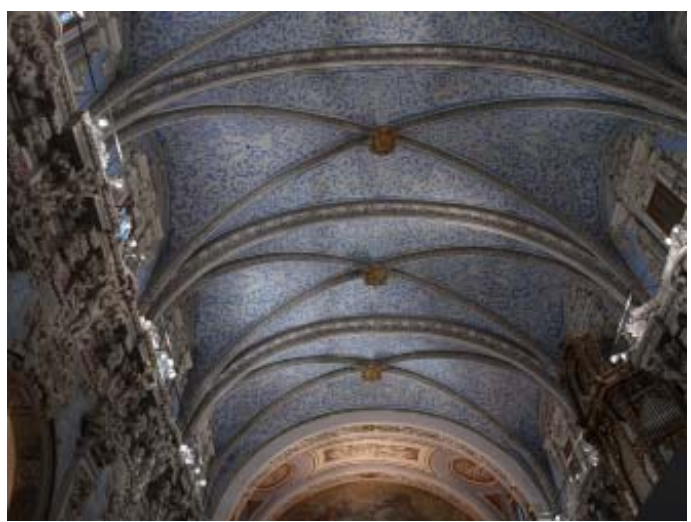

- Fig. 10. Interior de la Iglesia de San Esteban en Valencia. Foto del autor.

El trabajo de Pilar Llopart sobre la iglesia de San Severo de Barcelona, cuyo in-

32 J. BÉRCHEZ y F. JARQUE, Arquitectura barroca valenciana, Valencia, 1993, pp. 34 y ss. J. BÉRCHEZ, La arquitectura barroca, Valencia, 1994, p. 311. terior se esgrafió a partir de 1702, aporta el término "entretallar"

Curiosa es la palabra "aplantillado", de la que el Marqués de Lozoya, Isabel Ceballos-Escalera y Luis Felipe de Peñalosa ${ }^{34}$ informan que se empleó en Segovia como sinónimo de esgrafiado y que evidentemente derivaría de la plantilla utilizada para dibujar los diseños sobre el revoco tierno. Aunque hoy ha caído completamente en desuso, "aplantillado" da idea del triunfo de la decoración estandarizada sobre las fachadas segovianas, aunque no haya sido la plantilla el único sistema empleado en esta demarcación para trazar los motivos ornamentales; de hecho, hasta muy finales del siglo XV la decoración se construía in situ, mediante el uso de reglas, escuadras y compases, y eso cuando no se trazaba a mano alzada.

En un sentido semejante a éste, otro grupo de vocablos llaman al procedimiento técnico por términos que aluden al tipo de decoración más común que le ha sido encomendada en un determinado lugar. Xysta, "emparrillados", es el nombre que reciben los esgrafiados geométricos de la población de Pyrgi, en la isla griega de Quíos $^{35}$.

A esta categoría debe pertenecer también "ajaraca", empleado comúnmente en México, aunque figura igualmente dentro del léxico que el arquitecto Alberto García Gil y el restaurador Graziano Panzieri han utilizado en algunos de sus escritos para refe-

${ }^{33}$ P. LLOPART, "Un monumento del barroco barcelonés: la iglesia de San Severo", D'Art, no 3-4, 1977, pp. 4-9.

${ }^{34}$ J. DE CONTRERAS Y LÓPEZ DE AYALA, MARQUÉS DE LOZOYA, Historia del Arte Hispánico, t. 2, Barcelona-Buenos Aires, 1940, pp. 442-443. L. F. DE PEÑALOSA Y CONTRERAS, "Los esgrafiados segovianos", en F. ALCÁNTARA, L. F. DE PEÑALOSA Y CONTRERAS y S. BERNAL MARTÍN, Op. cit., [s.p.]. I. DE CEBALLOS-ESCALERA, Segovia Monumental, Madrid, 1953, p. 83.

${ }^{35}$ J. FERNÁNDEZ (coord.), Islas griegas, Madrid, 1991, p. 173. 
rirse los esgrafiados segovianos ${ }^{36}$; García Gil es un profundo admirador y conocedor del "país azteca", de ahí seguramente el empleo de este término. Analicemos el significado y el empleo de esta palabra. En 1849 -por ahora no hemos encontrado ninguna evidencia escrita anterior a esta fecha-, el glosario de términos que incluye el Catálogo de la Real Armería de Madrid, define "ajaraca" como "Especie de adorno formando lazos, y que se nota en muchos objetos de orijen ó fabricacion morisca. Hoy llaman á esta clase de lazos, lazería" ${ }^{37}$. Da la impresión de que ya por entonces se trataba de un término obsoleto en el lenguaje coloquial, pero que debía ser de esas palabras sonoras que son gustosas a sensibilidades refinadas, no exentas de un prurito de erudición, como ejemplifican por entonces los textos de Pablo Piferrer o José de Madrazo: “Encima, en lo que podríamos llamar friso de toda la portada, aparece un rótulo en grandes mayúsculas bizantinogóticas, que siguiendo el mismo carácter de toda la obra, semejan un arabesco, a guisa de letras floreadas con que enriquecían los mahometanos las ajaracas o almocárabes..." ${ }^{\prime 38}$. Quizá al calor del interés por los estilos históricos, volvemos a encontrar nuevas referencias en 1857 (Manuel de Assas, Monumentos de estilo mahometano desde el siglo VIII al siglo XVI) ${ }^{39}, 1876$ (Glosario de antiguos vocablos

${ }^{36}$ A. GARCÍA GIL, La arquitectura del monasterio de San Antonio el Real de Segovia, Segovia, 2009, pp. 83, 84, 133 y 170 . A. GARCÍA GIL y G. PANZIERI, “Culto oculto: materia y significado", Actas I Jornadas Internacionales Arte y Ciudad, Madrid, 24 y 25 de noviembre de 2011, Madrid, 2012, p. 52.

${ }^{37}$ Catálogo de la Real Armería, mandado formar por S.M., siendo Director General de Reales Caballerizas, Armería y Yeguada, el Excmo. Sr. Don José María Marchesi..., Madrid, 1849, p. 6.

${ }^{38}$ P. PIFERRER, Recuerdos y bellezas de España, para dar a conocer sus monumentos, antigüedades, paysajes, etc., Principado de Cataluña, Barcelona, 1839, p. 321. Otra alusión puede verse en P. DE MADRAZO, Sevilla y Cádiz, España. Sus Monumentos y Artes. Su Naturaleza e Historia, Barcelona, 1884, p. 640.

${ }^{39} \mathrm{M}$. DE ASSAS, "Monumentos de estilo mahometano desde el siglo VIII al siglo XVI", Semanario Pintoresco Español, nº 41, 1857, p. 322. de arquitectura $y$ de sus artes auxiliares $)^{40}$ y 1887 (J. Adeline, Vocabulario de términos de arte ${ }^{41} \mathrm{y}$ Eduardo de Echegaray, Diccionario Etimológico de la Lengua Española ${ }^{42}$ ), en las que queda claro que su significado tiene que ver con la ornamentación y no con la técnica empleada para su confección. Aun así, y ante el silencio de las fuentes escritas, no deja de ser sugerente la hipótesis de que "ajaraca" hubiera podido aplicarse desde tiempos medievales a la técnica del esgrafiado, sobre todo si tenemos en cuenta que algunos documentos del siglo XV se refieren a la pintura de carácter mudéjar, realizada frecuentemente sobre grafito inciso, con la expresión "echar cintas" $^{\prime 4}$, en clara alusión a los motivos de entrelazo que con ella se realizaban. ¿Se trata entonces de un término olvidado en España, pero que ha pervivido en México desde la colonización? La respuesta que por ahora dan las fuentes es negativa, quedando la incógnita de su empleo en el lenguaje hablado. Gabriela Sánchez Reyes, investigadora que ha profundizado específicamente en este asunto, ha concluido que el uso de "ajaraca", aplicado a los esgrafiados mexicanos, es sorprendentemente reciente, constatando su aparición en la década de los años treinta del siglo pasado; posteriormente, se irá generalizando en los setenta y ochenta, cuando se "bautiza" a algunos inmuebles del Distrito Federal con el sobrenombre de "Casa de las Ajaracas" (Fig. 11) y se incluye su definición en el Vocabulario Arquitectónico Ilustrado (1975): “Ornamento en forma de la-

${ }^{40}$ E. MARIÁTEGUI, Glosario de algunos antiguos vocablos de arquitectura, $y$ de sus artes auxiliares, Madrid, 1876 , pp. 5 y 76.

${ }^{41}$ J. ADELINE, Op. cit., p. 25.

${ }^{42}$ E. DE ECHEGARAY, Diccionario general etimológico de la lengua española. Edición económica arreglada del Diccionario Etimológico de D. Roque Barcia, del de la Academia Española, y de otros trabajos importantes de sabios etimologistas, corregida y aumentada considerablemente, t. I, Madrid, 1887, p. 168.

${ }^{43}$ C. RALLO GRUSS, Aportaciones a la técnica y estilística de la Pintura Mural en Castilla al final de la Edad Media, Tesis doctoral defendida en la Universidad Complutense de Madrid, 1999, p. 38. 
zos o listones, derivados de la arquitectura árabe, trabajado en estuco esgrafiado sobre paramentos de los muros" 44 . El hecho de que algunos esgrafiados mexicanos empleen lacerías, formadas frecuentemente por el desarrollo de estrellas de ocho puntas, debió llevar a identificar el proceso técnico por el nombre genérico y más erudito del diseño con él construido, en un momento en el que la arquitectura neocolonial hacía furor.

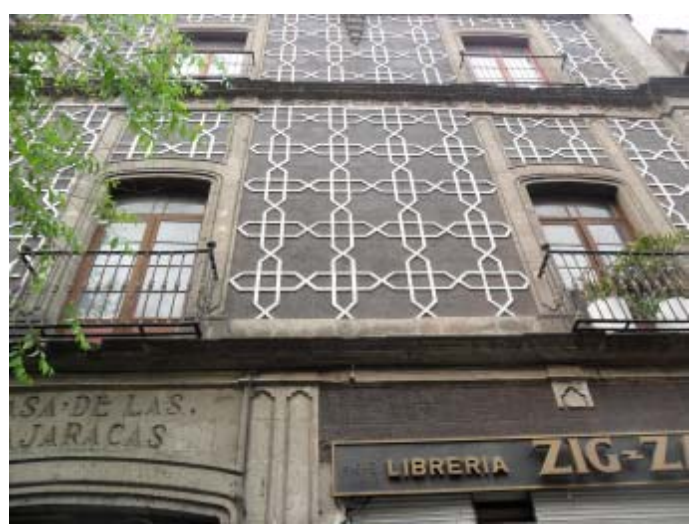

- Fig. 11. Imagen de uno de los inmuebles conocidos en México D. F. como "Casa de las Ajaracas". Foto del autor.

\section{LOS OTROS ESGRAFIADOS}

Hemos comenzado este artículo detallando muchos de los inconvenientes que el esgrafiado mural ha encontrado para afianzarse en el conocimiento general y en la Historia del Arte en particular. Aún queda por abordar otro fenómeno que ha generado confusión, incluso a un nivel tan elemental como el de diccionarios y enciclopedias: su presencia en otras disciplinas artísticas, aplicado a soportes muy diferentes, circunstancia que a veces ha aprovechado la historiografía para establecer relaciones entre diferentes técnicas y oficios.

En 1892, Heywood Sumner -artista inglés que practicó el esgrafiado mural con

${ }^{44}$ G. SÁNCHEZ REYES, “Reflexiones en torno a un motivo ornamental en la arquitectura de la ciudad de México: ajaracas o lazos de ocho", Boletín de Monumentos Históricos, no 21, 2011, pp. 125-132. gran maestría, así como la arqueología- relacionó los petroglifos prehistóricos con el esgrafiado mural, afirmando que "las palabras italianas Graffiato, Sgraffiato o Sgraffito significan "rayado", siendo el trabajo de rayado la más antigua expresión gráfica y de decoración de superficies" ${ }^{45}$. La afirmación de Sumner se constata en algunos sinónimos de "esgrafiado" que es posible encontrar en diferentes lenguas, así como en su significado. Scratched ornament se traduce del inglés como "decoración rayada"46; lo mismo ocurre con la palabra catalana esgarrapat, literalmente "rayado", menos utilizada que esgrafiat; en alemán, tienen una traducción semejante a estos vocablos, las palabras Kratzputz o Ritzputz; por último, los esgrafiados de la ciudad mauritana de Walata se denominan takhtad, término derivado de la raíz khadd, "hacer un surco" ${ }^{47}$.

También sobre piedra se han realizado desde época medieval finas decoraciones talladas sobre pavimentos y lápidas de mármol blanco, cuyas líneas excavadas se volvían a rellenar con una pasta oscura. No sabemos dónde surgió el procedimiento, encontrándose en lugares tan distantes como las catedrales de Canterbury o Siena, pero lo cierto es que a los pavimentos sieneses se alude habitualmente con el nombre de "esgrafiados" 48 .

La aparición de nuestro procedimiento sobre vidrio quizá esté relacionada con la talla de ese material, técnica muy difundida en el periodo final romano y en el Imperio Sasánida. Junto al vidrio rayado existe tam-

${ }^{45}$ H. SUMNER, "Of sgraffito work", The decorator and Furnisher, vol. 20, nº 2, 1892, pp. 50-51.

${ }^{46}$ G.W.R. WARD (ed.), The Grove Encyclopedia of Materials and Techniques in Art, New York, 2008, p. 592.

${ }^{47}$ J. A. SHOUP, “Traditional Wall Art in Walata: Caravan City in the Eastern Hawdh", Anaquel de Estudios Árabes, no 22, 2011, p. 187.

${ }^{48} \mathrm{~J}$. FAWCETT, Historic floors, their care and conservation, Bath, 2001, p. 18. J. STEVENS CURL, The Egyptian revival. Ancient Egypt as the Inspiration for design motifs in the West, [s.1.], 2006, p. 89. R. MUNMAN, Sienese Renaissance Tomb Monuments, Philadelphia, 1993, p. 63. 
bién la variante del vidrio dorado y esgrafiado, cuya invención se sitúa con ciertas dudas en Oriente, durante el siglo $\mathrm{XI}^{49}$. En este caso, tras adherir al recipiente una fina lámina de oro, se retira con un punzón todo aquel dorado que rodea a la figura ornamental. El mismo concepto y parecido proceso se ha aplicado a la forja dorada y esgrafiada.

Las decoraciones que emplean esta técnica sobre objetos de cerámica se remontan al Neolítico. El procedimiento supone, de nuevo, pintar eliminando pintura, es decir, se rasca la capa pictórica del engobe para descubrir el color del propio soporte, practicando para ello un decapado selectivo que propicia la combinación de ambos cromatismos en el resultado final. Griegos y etruscos perfeccionarán el sistema durante la Antigüedad, con sus características producciones de figuras negras y rojas, en las que se esgrafían finas líneas al interior de las siluetas para destacar rasgos físicos y anatómicos, detalles ornamentales, etc. Puntualizaremos al respecto que en algunos idiomas se denomina sgraffiato al esgrafiado sobre cerámica, para distinguirlo del esgrafiado mural o sgraffito ${ }^{50}$.

Los etruscos destacarán igualmente en la producción de vasos y espejos de bronce con escenas grabadas muy similares a las del esgrafiado cerámico.

Cathleen S. Hoeniger ha sugerido que la técnica empleada en la cerámica esgrafiada persa del siglo XIII pudo influir en la aparición del procedimiento aplicado a la policromía de la escultura en madera, cuyas primeras evidencias en Italia aparecen a finales del Duecento y principios del Trecento. Desde este campo, muy posiblemente, el esgrafiado saltó a la pintura por esas mismas fechas, destacando entre sus cultivadores primerizos Simone

${ }^{49}$ J. NAVARRO PALAZÓN y P. JIMÉNEZ CASTILLO, Siyāsa: estudio arqueológico de un despoblado andalusí (ss. XI-XIII), Murcia, 2007, p. 320.

${ }^{50} \mathrm{~W}$. WESTERHOFF, Sgraffito in Österreich, Eine Übersicht, Krems, 2009, p. 15.
Martini ${ }^{51}$. No sabemos cuándo comenzó a llamarse esgrafiado a este proceso en Italia; de hecho, Cennino Cennini, a pesar de que dedica numerosas páginas de Il Libro dell'Arte a explicar sus diferentes particularidades y usos, lo define con una frase y no con un término: Come si disegna, si gratta, e si grana un drappo d'oro o d'argento ("De cómo se dibuja, se rasca y se granea un brocado de oro o de plata") $)^{52}$. Sin embargo, las primeras noticias documentales del empleo de la palabra "esgrafiado" en castellano se refieren a este tipo de decoración. Así, en el archivo de la catedral de Toledo se consigna: "En seys dias del mes de mayo de 1559 años, di çedula que diesen a aguilar pintor [...] de los frisos esgrafiados seys ducados..." ${ }^{\prime 23}$. Ese mismo año se establecen allí las condiciones para realizar un Calvario con el escultor Nicolás de Vergara, quien se compromete a que "...el dicho crucifijo y el paño y diadema y titulo de la cruz a de ser muy bien dorado y estofado y esgrafiado..." ${ }^{54}$. Un siglo después, en 1650, tenemos noticia en Barcelona del gremio dels estofadors, dauradors, esgrafiadors y encarnadors ${ }^{55}$, con ocasión de una reclamación ante el Consejo de esta ciudad. En 1703, un litigio entre gremios se resolvió allí mismo con la orden de que los doradores no pudieran llamarse pintores de retablos y que sólo se pudieran intitular y cognominar dauradors, stofadors o esgrafiadors y com a tals fer lo tocant a la art de la dauradura, stofadura y sgra-

${ }^{51}$ C. S. HOENIGER, "Cloth of Gold and Silver: Simone Martini's Techniques for Representing Luxury Textiles", Gesta, XXX/2, 1991, p. 156. H. B. J. MAGINNIS, The World of the Early Sienese Painter, with a translation of the Sienese Breve dell'Arte dei Pittori by Gabriele Erasmi, [s.l.], 1992, p. 98.

${ }^{52}$ C. CENNINI, El Libro del Arte, Madrid, 2009, cap. CXLII, p. 177.

${ }^{53}$ Datos documentales para la historia del Arte Español II. Documentos de la catedral de Toledo; colección formada en los años 1869-74 y donada al Centro en 1914, por D. Manuel R. Zarco del Valle, T. II, Madrid, 1916, pp. 102-103.

${ }^{54}$ Ibídem, p. 105.

${ }^{55}$ R. NONAT COMAS, Estudi dels Esgrafiats de Barcelona, Barcelona, 1913, pp. 150 y ss. 
fiadura ${ }^{56}$. ¿Qué función cumplía el esgrafiado en tales trabajos? Previamente a la labor de policromía de una escultura o de una tabla, se preparaba la madera, labor conocida como "aparejo"; en esta fase se alisaban las superficies, procurando llenar todas las posibles grietas y huecos, aplicándose para ello varias capas de cola y yeso, que después se pulían. La fase de "dorado" -en la variedad conocida como "al agua"- comenzaba pintando la pieza con una arcilla untuosa y rojiza llamada "bol"; tras humedecer esta pintura, sobre ella se fijaban los panes de oro, plata, estaño dorado o cobre, que posteriormente recibían un bruñido con una piedra de ágata. A continuación se procedía al "estofado" o policromado de la pieza, cubriendo el oro con una pintura al temple; cuando esta capa pictórica tomaba cierta consistencia, se rayaban o esgrafiaban ciertos motivos, previamente dibujados, que descubrían en parte el oro del fondo ${ }^{57}$. Dado que por lo general se simulaban así ricos paños de brocado, el proceso en su conjunto se llamó "estofado", del italiano stoffa, "tela", aunque propiamente la labor de estofado era la de la pintura (sobre todo aquella que se aplicaba a la imitación de tejidos), en contraposición a la del rayado, que corresponde al esgrafiado. Por último se procedía al policromado más exquisito, el "encarnado", que buscaba semejar el tono de la piel sobre rostros, manos, etc. La vecindad técnica del esgrafiado mural y de este otro aplicado sobre fondos de oro, llevó a algunos autores, como Ramón Nonat Comas, a sugerir que detrás de ambas disciplinas pudieran encontrarse los mismos artífices $^{58}$, si bien, no han desarrollado esta interesante hipótesis más allá de su enunciado. Aun así, esta insinuación siempre me ha seducido, sobre todo por el hecho de que el estofado se aplicó también a la pintura mural, detalle en el que no parecen haber caído estos

\footnotetext{
${ }^{56}$ A. PÉREZ SANTAMARÍA, Escultura barroca a Catalunya, Lleida, 1988, p. 85.

${ }^{57}$ C. CENNINI, Op. cit., cap. CXLII, p. 177.

${ }^{58}$ R. NONAT COMAS, Op. cit., pp. 150 y ss. Sus ideas han sido literalmente repetidas por M. CASAS I HIERRO, Esgrafiats, Tarragona, 1983.
}

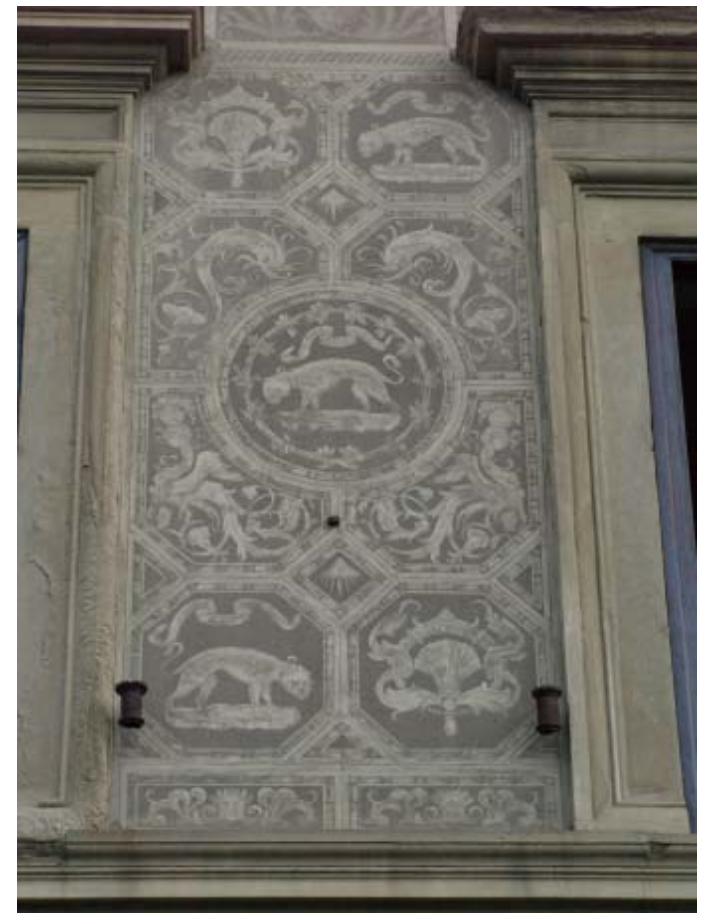

- Fig. 12. Detalle de la fachada del Palacio Lanfredini en Florencia, con esgrafiados de Andrea di Cosimo Feltrini. Foto del autor.

investigadores. Cennino Cennini ya describió su proces ${ }^{59}$, pero este tratado nos resulta aún más valioso por detallar un procedimiento complementario que los muralistas utilizaban para enriquecer sus trabajos con relieves ornamentales, objeto también del dorado, cuya cercanía al concepto de esgrafiado mural es más que evidente: “Hay que conseguir el relieve de la aureola sobre el revoco fresco con una pequeña llana, de la forma siguiente: cuando hayas dibujado la cabeza de la figura, coge el compás y traza la corona. Después toma un poco de mortero, bien graso, preparado a modo de ungüento o pasta, y estuca con él, con los bordes más altos y rebajando hacia el contorno de la cabeza. Luego vuelve a coger el compás una vez que hayas pulido bien dicho mortero, y con el cuchillo ve cortándolo siguiendo el perfil marcado con el compás y quedará en relieve ${ }^{\prime 60}$. Difícil de testimoniar es la versatilidad de los creadores en los medios técnicos que nos ocupan. Artistas y tratadistas

${ }^{59}$ C. CENNINI, Op. cit., cap. CXLIII, p. 179.

${ }^{60} \mathrm{Ibídem}$, cap. CII, pp. 144-145. 
no aclaran demasiado nuestras dudas, dado que con frecuencia han considerado al esgrafiado mural como una técnica pictórica más, caso de Vasari; precisamente su tratado informa que Andrea di Cosimo Feltrini (Fig. 12), de quien aseguraba que fue el primero en hacer esgrafiados sobre las fachadas de Florencia, formó una compañía con otros dos socios que se dedicaban al dorado, Mariotto di Francesco y Raffaello di Biagio ${ }^{61 .}$

En contra de lo que a priori pudiera pensarse, el arte contemporáneo ha seguido contando con el esgrafiado, enriqueciendo sus prestaciones.

El pintor Benjamín Palencia, por ejemplo, gustaba en ocasiones de trazar finas líneas en sus pinturas; para ello, cuando el óleo estaba aún fresco, utilizaba la punta de una espátula o el extremo opuesto de un pincel para retirar el color superficial, descubriendo otra coloración aplicada previamente como fondo o dejando al descubierto el lienzo.

Creadores como Max Ernst, Paul Klee, Joan Miró o Antoni Tàpies emplearon el gratta$g e$, en esencia un raspado de la última capa pictórica que descubría en parte la película o películas cromáticas subyacentes, dotando al efecto final de curiosas texturas visuales.

Entre 2012 y 2013, el artista de origen sudafricano Marc Bowditch ha desarrollado una técnica de pintura a la acuarela-esgrafiado que él denomina unpainting: sobre un papel consistente, pinta con esta técnica en una o varias capas superpuestas, sobre las que después, con ayuda de pinceles húmedos, actúa para retirar selectivamente la pintura, creando curiosos y sorprendentes juegos de transparencias.

Uno de los representantes más destacados del llamado Urban Art, es el joven artista portugués Alexandre Farto "Vhils", quien ha plasmado impactantes y gigantescos rostros de personajes anónimos, cargados frecuentemente de un contenido dramatismo, sobre tapias, fachadas, muros y medianerías

${ }^{61}$ G. VASARI, Op. cit., p. 442. de edificios abandonados e incluso ruinosos de medio mundo ${ }^{62}$. El método de trabajo que emplea consiste en elegir un muro enfoscado y pintado, o sobre el que se han superpuesto diferentes acabados a lo largo de su existencia. Después, procede a dibujar el motivo elegido a base de superficies más o menos planas de color, que respetan, no obstante, buena parte del paramento original. La mayoría de esas manchas va a ser eliminada mediante el empleo martillos neumáticos, maceta $\mathrm{y}$ cortafríos, etc., hasta descubrir el enfoscado o la propia fábrica del muro.

Sin embargo, una de las aportaciones más interesantes al esgrafiado contemporáneo vendrá de la mano del equipo formado por Carl Nesjar y Pablo Picasso, quienes, empleando como medio un chorro de arena sobre la superficie de un tipo específico de hormigón -el naturbetong-, crearán un buen número de grandes murales y esculturas (Fig. 13).

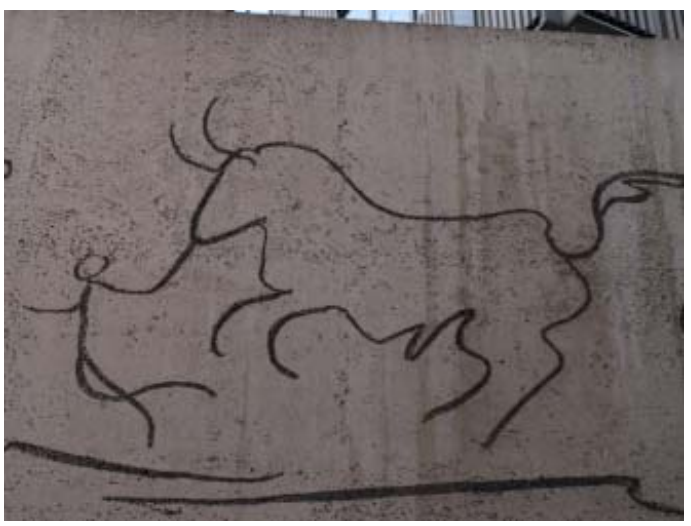

- Fig. 13. Pormenor de la fachada del Colegio de Arquitectos de Cataluña y Baleares en Barcelona, realizados por Carl Nesjar, sobre diseños de Pablo Picasso. Foto del autor.

A la historia del esgrafiado le quedan aún muchas y sorprendentes páginas por escribirse; creo que el mejor favor que podemos brindarle es hacerlo desde una terminología adecuada, base sobre la que será más fácil construir una rigurosa historiografía.

\footnotetext{
${ }^{62}$ Hay algunas excepciones como los murales que ya se exhiben en varios museos o el de la escalera de la Escuela Secundaria de Seixal (Portugal), donde estudió en su juventud.
} 